\title{
A self-assessment study of procedural skills of doctors in peri-urban district hospitals of Gauteng, South Africa
}

\begin{tabular}{|c|c|}
\hline \multicolumn{2}{|c|}{$\begin{array}{l}\text { Authors: } \\
\text { Neetha J. Erumeda } \\
\text { Ian D. Couper } \\
\text { Leena S. Thomas }\end{array}$} \\
\hline \multicolumn{2}{|c|}{$\begin{array}{l}\text { Affiliations: } \\
{ }^{1} \text { Ekurhuleni Health District } \\
\text { Services, Gauteng } \\
\text { Department of Health, } \\
\text { Germiston, South Africa }\end{array}$} \\
\hline \multicolumn{2}{|c|}{$\begin{array}{l}{ }^{2} \text { Department of Family } \\
\text { Medicine, University of the } \\
\text { Witwatersrand, Johannesburg, } \\
\text { South Africa }\end{array}$} \\
\hline \multicolumn{2}{|c|}{$\begin{array}{l}{ }^{3} \text { Ukwanda Centre for } \\
\text { Rural Health, Stellenbosch } \\
\text { University, Stellenbosch, } \\
\text { South Africa }\end{array}$} \\
\hline \multicolumn{2}{|c|}{$\begin{array}{l}{ }^{4} \text { Department of Community } \\
\text { Medicine, University of the } \\
\text { Witwatersrand, Johannesburg, } \\
\text { South Africa }\end{array}$} \\
\hline \multicolumn{2}{|c|}{$\begin{array}{l}\text { Corresponding author: } \\
\text { Neetha Erumeda, } \\
\text { neetha.erumeda@wits.ac.za }\end{array}$} \\
\hline \multicolumn{2}{|c|}{$\begin{array}{l}\text { Dates: } \\
\text { Received: } 12 \text { Oct. } 2018 \\
\text { Accepted: } 06 \text { Feb. } 2019 \\
\text { Published: } 28 \text { May } 2019\end{array}$} \\
\hline \multicolumn{2}{|c|}{$\begin{array}{l}\text { How to cite this article: } \\
\text { Erumeda NJ, Couper ID, } \\
\text { Thomas LS. A self-assessm } \\
\text { study of procedural skills o } \\
\text { doctors in peri-urban } \\
\text { district hospitals of Gauten } \\
\text { South Africa. Afr J Prm } \\
\text { Health Care Fam Med. } \\
\text { 2019;11(1), a1975. } \\
\text { https://doi.org/10.4102/ } \\
\text { phcfm.v11i1.1975 }\end{array}$} \\
\hline \multicolumn{2}{|c|}{$\begin{array}{l}\text { Copyright: } \\
\text { (C) 2019. The Authors. } \\
\text { Licensee: AOSIS. This work } \\
\text { is licensed under the } \\
\text { Creative Commons } \\
\text { Attribution License. }\end{array}$} \\
\hline Read online: & \\
\hline ㅁitiv & $\begin{array}{l}\text { Scan this QR } \\
\text { code with your } \\
\text { smart phone or } \\
\text { mobile device } \\
\text { to read online. }\end{array}$ \\
\hline
\end{tabular}

Background: Several studies have been carried out on procedural skills of doctors in district hospitals in rural South Africa. However, there is insufficient information about skills of doctors in peri-urban district hospitals. This paper attempts to supplement this vital information.

Aim: The aim of the study was to determine self-reported levels of competence in procedural skills of doctors in peri-urban district hospitals and to assess factors influencing this.

Setting: The study was undertaken in three district hospitals in two health districts of Gauteng Province.

Methods: A cross-sectional descriptive study using a self-administered questionnaire was undertaken in three district hospitals in two health districts of Gauteng Province. The questionnaire assessed procedural skills based on district health service delivery requirements for doctors in district hospitals using a modified skill set developed for family medicine training in South Africa.

Results: There was a wide range of self-reported competence and experience among doctors for various skill sets. Doctors were generally more competent for procedures in general surgery, medicine, orthopaedics, obstetrics and gynaecology and paediatrics than anaesthesia, ear, nose and throat and ophthalmology. There were statistically significant associations between age and overall anaesthetic competence $(p=0.03)$; gender and overall competence in surgery $(p=0.03)$, orthopaedics $(p=0.02)$ and urology $(p=0.005)$; years of experience and overall competence in dermatology skills; current hospital and overall competence in anaesthesia $(p=0.01)$, obstetrics and gynaecology $(p=0.015)$ and dermatology skills $(p=0.01)$.

Conclusion: This was one of the first studies to look at self-reported procedural competence of doctors in a peri-urban setting in South Africa. The results highlight the need for regular skills audits, standardised training and updating of skills of doctors in district hospitals.

Keywords: generalist doctors; procedural skills; self-reported competence; peri-urban district hospital; family medicine training.

\section{Introduction}

According to the World Health Organisation (WHO) model of effective health systems, developing the right cadres of health workers with an appropriate skills mix is an important consideration for any health system. ${ }^{1}$ As South Africa transforms its health system towards Universal Health Coverage (UHC), ${ }^{2}$ a key consideration is the re-organisation of health services and the health workers required for this. This is further elaborated in the White Paper on the National Health Insurance scheme (NHI), ${ }^{3}$ seen as a vehicle for UHC elaborating on the services to be rendered by health districts.

\section{According to $\mathrm{WHO}$, the district health system is defined as:}

a network of primary care health facilities that deliver a comprehensive range of promotive, preventive and curative health care services to a defined population with active participation of the community; under the supervision of a district hospital and district health management team. ${ }^{4}$

In the South African setting, a district hospital is the first-level referral hospital for patients from community-based health services. ${ }^{5}$ District hospitals are classified as rural or urban depending on their location. Peri-urban hospitals are those that are in the peripheries of urban areas. 
District hospitals also function as a gateway for specialised care. ${ }^{5}$ Generalist doctors in the context of this paper are medical officers without any postgraduate training in family medicine. Most doctors in district hospital settings are generalists, providing holistic care and clinical procedures as outlined in the district hospital service-level package. ${ }^{5,6,7}$ The family physicians are medical specialists with postgraduate training in family medicine and are considered as expert generalists as they fulfil roles such as care provider, competent clinician and a capacity builder. ${ }^{6,8}$

District health services in rural settings often have greater needs for clinical procedures, hence more need for skills in doctors in that context. Many studies have identified the skills gap of doctors working in rural settings. ${ }^{9}, 10,11,12,13,14,15$ According to Peters et al., the role and scope of practice of general practitioners (GPs) in urban and peri-urban district hospitals in South Africa is wider and not as well documented. ${ }^{16}$ Peters and colleagues also showed the need of medical officers to be competent generalists who are able to deal with primary care, trauma and emergency care skills, and for adequate surgical skills to perform obstetric, orthopaedic and other surgical procedures. ${ }^{16}$ A study conducted in district hospitals of the Western Cape showed that the perceived competence ratings in emergency and trauma, inpatient and outpatient services were higher in older and more experienced practitioners. ${ }^{11}$ Their knowledge varied considerably according to their education, training, previous work experiences and the context (rural or urban) of the district hospital. ${ }^{11}$

In South Africa, family physicians play an important role in the training and education of family medicine registrars, generalist medical officers, medical students, interns and clinical associates in district hospitals. ${ }^{17}$ Because of inadequate numbers of family physicians in district health services, the generalist medical doctors often function as in-service trainers for these students. These generalist doctors have many years of experience in a particular discipline, and therefore the assumption is that they are able to contribute significantly to the training. ${ }^{7}$ Existing generalists in district hospitals may be competent in specific clinical areas, and often because of long years of service, their skill competency may be more than newly qualified family physicians, thus making them a valuable potential teaching resource. ${ }^{8}$ The procedural skills of these generalist doctors and family physicians should be aligned to service delivery contexts in South Africa, both urban and rural, to respond to increasing health service demands. Although full-time family medicine training has evolved since this study was initially conducted, and continues to evolve, there are still inadequate numbers of family physicians in South African district hospitals. ${ }^{18}$ Hence clinical procedures in district hospitals are still mostly done by generalist medical officers, with these hospitals continuing as training sites for postgraduate family medicine registrars, undergraduate medical students, nurses and midlevel health workers. This study, therefore, provides an important baseline for district health service strengthening in South Africa.
The required skill set for qualified family physicians used in the current training of family medicine registrars and medical officers was developed through a national Delphi process, ${ }^{19}$ and then this was further refined by the eight medical schools in South Africa. The skill set is inclusive of the requirements of the district hospital service package for procedures to be done in district hospitals. ${ }^{5}$

Internationally, many developed countries such as the United Kingdom, ${ }^{20}$ the United State ${ }^{21}$ and Canada ${ }^{22,23,24}$ are following a similar trend of developing context-specific skill sets for their family medicine residency training programmes in rural and urban settings. According to Kalu et al., there is a suggestion that there should be a separate skills list for generalist doctors working in urban and rural settings in South Africa. ${ }^{25}$ There may, therefore, be a greater need for doctors with context-specific procedural skills in anaesthesia, obstetrics and gynaecology (O\&G) and surgery for GPs working in rural and peri-urban district hospitals in South Africa to meet the current context requirements.

Few South African studies have explored the procedural skills of doctors in urban and peri-urban district hospital settings. Hence the aim of this study was to assess competence in procedural skills and the factors that influence it among doctors working in district hospitals in Gauteng Province. It is anticipated that the findings of this study, set in an urban area, in one of the most populated provinces of South Africa, will add to the body of local knowledge and inputs to the current deliberations on the role of GPs and family physicians within the proposed NHI.

\section{Methods Study design}

A cross-sectional descriptive study was conducted during the period October and November 2009 using a self-assessment questionnaire.

\section{Setting}

Three peri-urban district hospitals in Gauteng Province were purposively selected. One of the hospitals, District Hospital A, had a service delivery model where all doctors were expected to be competent in all clinical disciplines, and were, therefore, rotated in all units. In the other two, hospitals B and $C$, health services were divided according to the various disciplines or units, and doctors could choose to work in only one, for example, outpatient department (OPD), maternity or theatre.

\section{Study population and sampling strategy}

All doctors working in the identified three district hospitals were invited to participate in the study. The number of doctors per district hospital ranged from 15 to 25 doctors. The study population included all categories of doctors working in the district hospital: community service doctors, GPs, medical officers, registrars in family medicine and family physicians. ${ }^{6,8}$ 


\section{Data collection}

Data were collected using a structured self-administered questionnaire. The questionnaire was distributed through the office of the hospital clinical managers, who assisted in distributing and collecting the completed questionnaires. The questionnaire was developed using the national department of health service delivery package for district hospitals ${ }^{5}$ and the modified procedural skills list developed by Mash et al. for family medicine registrar training in South Africa ${ }^{19}$; it was further refined for the local study context. The tool was piloted in one of the study sites; as there were no major challenges or changes to the tool, these results were also incorporated into the main study. The questionnaire had two parts: the first part included questions about the general characteristics of the participants, such as 'In which department or discipline do you spend most of your time?', 'Where did you train for your undergraduate medical degree?', 'Have you completed any postgraduate family medicine training in South Africa?' and 'If no, are you currently enrolled for family medicine training?' The second part required doctors to rate their own competency against a list of skills, categorised in 10 domains. Competence was interpreted based on self-reported confidence of the doctor in performing a procedure, with ratings from 0 to 3 . The response ' 0 ' indicated unfamiliarity with the procedure; ' 1 ' indicated ability to explain the procedure to a patient (theoretical knowledge) but not able to perform it; ' 2 ' indicated ability to perform a procedure with support and ' 3 ' indicated the ability to perform a procedure independently.

Doctors who rated themselves as ' 3 ' on any item were then asked to indicate their experience by providing the approximate number of times they had performed the respective procedure independently, by selecting one of three options: less than 5 times was categorised as $3 \mathrm{~A}, 5-10$ as $3 \mathrm{~B}$ and more than 10 as 3C. For example, if Dr $X$ had performed endotracheal intubation independently and had done such procedures 8 times, then Dr X would score as ' $3 \mathrm{~B}$ '. If $\mathrm{Dr} Y$ had performed a pleural tap with support, then Dr Y would score a ' 2 '.

\section{Data analysis}

Data were collated using Epi Info version 3.5.1 software. ${ }^{26}$ Firstly, descriptive statistics in the form of frequencies and percentages were used to determine the competence and experience in each of the procedures. If more than $75 \%$ of doctors were able to perform a procedure independently, then that procedure was categorised as highly competent; if $50 \%-75 \%$, then that was classified as a competent procedure and if less than $50 \%$, then that was reported as not a competent procedure. Secondly, overall levels of competence in each group of procedural skills were determined. Doctors were categorised into overall not competent, competent or highly competent based on the number of procedures they could do independently in each clinical discipline. Associations between overall competence and categorical variables such as age, gender, years of experience, clinical discipline where most time was spent, current hospital, undergraduate training and postgraduate family medicine training were determined using Chi-square and Fischer's exact tests. A $p$-value of less than 0.05 was considered statistically significant.

\section{Ethical considerations}

Ethical approval for this study was obtained from the Human Research Ethics Committee of the University of the Witwatersrand (M070202) and the Gauteng Provincial Department of Health.

\section{Results}

There were 70 doctors eligible for the study, with 59 completing the questionnaires - an $84 \%$ response rate (Table 1). Sixty-three per cent were males and $41 \%$ of the participants belong to the age group 35-44 years. Twentyeight participants $(48.3 \%)$ had more than 10 years of experience. A majority of participants (57.6\%) spent most of

TABLE 1: General characteristics of study participants.

\begin{tabular}{|c|c|c|}
\hline \multirow[t]{2}{*}{ Characteristics } & \multicolumn{2}{|c|}{ Frequency } \\
\hline & $n$ & $\%$ \\
\hline \multicolumn{3}{|l|}{ Age (years) } \\
\hline $25-34$ & 16 & 30.5 \\
\hline $35-44$ & 21 & 40.7 \\
\hline $45-54$ & 15 & 17.0 \\
\hline 55 and above & 7 & 11.9 \\
\hline \multicolumn{3}{|l|}{ Gender } \\
\hline Male & 37 & 63.0 \\
\hline Female & 22 & 37.0 \\
\hline \multicolumn{3}{|l|}{ Years of experience } \\
\hline 2 years or less & 3 & 5.2 \\
\hline $3-5$ years & 17 & 29.3 \\
\hline $6-10$ years & 10 & 17.2 \\
\hline Above 10 years & 28 & 48.3 \\
\hline \multicolumn{3}{|l|}{ Discipline in which most time is spent } \\
\hline Casualty & 17 & 28.8 \\
\hline OPD/General practice/Family medicine & 17 & 28.8 \\
\hline Medicine & 8 & 13.6 \\
\hline Maternity & 8 & 13.6 \\
\hline Surgery & 3 & 15.1 \\
\hline HIV clinic & 3 & 15.1 \\
\hline Psychiatry & 1 & 1.7 \\
\hline Anaesthesia & 1 & 1.7 \\
\hline ENT & 1 & 1.7 \\
\hline \multicolumn{3}{|l|}{ Place of undergraduate training } \\
\hline South Africa & 29 & 49.0 \\
\hline Outside South Africa & 30 & 51.0 \\
\hline \multicolumn{3}{|c|}{ Postgraduate family medicine training (part-time) } \\
\hline No & 49 & 83.1 \\
\hline Yes & 10 & 17.0 \\
\hline \multicolumn{3}{|l|}{ Current family medicine training (full-time) } \\
\hline No & 54 & 91.5 \\
\hline Yes & 5 & 8.5 \\
\hline \multicolumn{3}{|l|}{ Current hospital } \\
\hline Hospital A & 15 & 25.4 \\
\hline Hospital B & 24 & 40.7 \\
\hline Hospital C & 20 & 33.9 \\
\hline
\end{tabular}


TABLE 2: Results of competence and experience in procedural skills among some procedures in various disciplines.

\begin{tabular}{|c|c|c|c|c|c|c|c|c|c|c|c|c|}
\hline \multirow[t]{3}{*}{ Procedural skills } & \multirow[t]{3}{*}{ Total $\dagger$} & \multicolumn{8}{|c|}{ Competence } & \multicolumn{3}{|c|}{ Experience $(n)$} \\
\hline & & \multicolumn{2}{|c|}{$\begin{array}{l}\text { Unfamiliar with } \\
\text { procedure (0) }\end{array}$} & \multicolumn{2}{|c|}{$\begin{array}{l}\text { Able to explain to } \\
\text { patient (1) }\end{array}$} & \multicolumn{2}{|c|}{$\begin{array}{l}\text { Able to do the procedure } \\
\text { with support (2) }\end{array}$} & \multicolumn{2}{|c|}{$\begin{array}{l}\text { Able to do the procedure } \\
\text { independently }\end{array}$} & \multirow[t]{2}{*}{$\begin{array}{c}3 A \\
(<5)\end{array}$} & \multirow[t]{2}{*}{$\begin{array}{c}3 B \\
(5-10)\end{array}$} & \multirow[t]{2}{*}{$\begin{array}{c}3 C \\
(>10)\end{array}$} \\
\hline & & $n$ & $\%$ & $n$ & $\%$ & $n$ & $\%$ & $n$ & $\%$ & & & \\
\hline Pleural tap & 59 & 1 & 1.7 & 0 & 0.0 & 1 & 1.7 & 5 & 96.6 & 1 & 1 & 52 \\
\hline Lumbar puncture & 59 & 1 & 1.7 & 0 & 0.0 & 2 & 3.4 & 56 & 94.9 & 1 & 1 & 52 \\
\hline Intercostal drain insertion & 59 & 1 & 1.7 & 1 & 1.7 & 2 & 3.4 & 55 & 93.2 & 1 & 2 & 51 \\
\hline Endotracheal intubation & 58 & 2 & 3.4 & 0 & 0.0 & 6 & 10.3 & 50 & 86.2 & 1 & 3 & 44 \\
\hline Caesarean section & 57 & 2 & 3.5 & 5 & 8.8 & 8 & 14.0 & 42 & 73.7 & 1 & 0 & 40 \\
\hline Spinal anaesthesia & 57 & 10 & 17.5 & 4 & 7.0 & 8 & 14.0 & 35 & 61.4 & 0 & 1 & 32 \\
\hline General anaesthesia & 54 & 12 & 22.2 & 5 & 9.3 & 11 & 20.4 & 26 & 48.1 & 0 & 1 & 23 \\
\hline Insertion of IUCD & 59 & 8 & 13.6 & 16 & 27.1 & 11 & 18.6 & 24 & 40.7 & 1 & 2 & 20 \\
\hline Appendicectomy & 59 & 9 & 15.3 & 7 & 11.9 & 21 & 35.6 & 22 & 37.3 & 6 & 2 & 14 \\
\hline Cricothyroidotomy & 57 & 18 & 32.0 & 19 & 33.0 & 14 & 25.0 & 6 & 11.0 & 4 & 1 & 1 \\
\hline Tracheostomy & 59 & 15 & 25.4 & 23 & 39.0 & 13 & 22.0 & 8 & 13.6 & 3 & 0 & 4 \\
\hline
\end{tabular}

IUCD, intrauterine contraceptive device.

$\dagger, n=59$.

TABLE 3: Procedural skills in which doctors rated themselves as highly competent.

\begin{tabular}{|c|c|c|}
\hline \multirow{2}{*}{$\begin{array}{l}\text { List of procedural skills in which } \\
\text { doctors rated themselves as highly } \\
\text { competent ( } 75 \% \text { and above) }\end{array}$} & \multicolumn{2}{|c|}{$\begin{array}{l}\text { No. of doctors who could perform the } \\
\text { procedure independently }(n=59)\end{array}$} \\
\hline & $n$ & $\%$ \\
\hline Intravenous infusion (paediatrics) & 56 & 100.0 \\
\hline Pleural tap & 57 & 96.6 \\
\hline Lumbar puncture (adult) & 56 & 94.9 \\
\hline I and D abscesses & 55 & 94.8 \\
\hline Insertion of nasogastric tube & 55 & 94.8 \\
\hline Urethral catheterisation & 55 & 94.8 \\
\hline Intercostal drain insertion & 55 & 93.2 \\
\hline Nasal packing & 55 & 93.2 \\
\hline Normal vaginal delivery & 54 & 93.0 \\
\hline Application of POP & 54 & 91.5 \\
\hline Lumbar puncture (paediatrics) & 53 & 93.0 \\
\hline Ear syringing & 53 & 89.8 \\
\hline Immobilisation of fractures & 53 & 89.8 \\
\hline Evacuation of uterus & 51 & 86.4 \\
\hline Removal of foreign body (ENT) & 51 & 86.4 \\
\hline Bartholin's abscess & 50 & 86.2 \\
\hline Endotracheal intubation & 50 & 86.2 \\
\hline Episiotomy and suturing & 50 & 84.7 \\
\hline Manual removal of placenta & 49 & 84.5 \\
\hline Papanicolou smear & 49 & 84.5 \\
\hline Reduction of dislocation & 47 & 79.7 \\
\hline Excision of bumps and lumps & 45 & 78.9 \\
\hline Debridement of wounds & 44 & 77.2 \\
\hline Suprapubic catheterisation & 44 & 77.2 \\
\hline Reduction of paraphimosis & 44 & 75.9 \\
\hline Removal of foreign body eye & 44 & 75.9 \\
\hline Ring block & 43 & 78.2 \\
\hline Suprapubic bladder puncture & 42 & 76.4 \\
\hline
\end{tabular}

POP, Plaster of Paris; ENT, ear, nose and throat.

their time in either OPD or casualty. Just more than half (51\%) of the participants received their undergraduate medical training outside of South Africa, namely, the Congo (60\%); Cuba (10\%); India, Poland and Nigeria (6.7\% each) and Uganda, Belgium and Bulgaria (3.3\% each).

The results showed that the doctors expressed varying level of competence and experience in different procedures (Table 2). Procedures in each discipline were grouped based on the percentage of doctors with the ability to do the
TABLE 4: Procedural skills in which doctors rated themselves as competent.

\begin{tabular}{lcc}
\hline $\begin{array}{l}\text { List of procedural skills in which } \\
\text { doctors rated themselves as competent }\end{array}$ & $\begin{array}{c}\text { No. of doctors who could perform the } \\
\text { procedure independently }(\boldsymbol{n}=\mathbf{5 9})\end{array}$ \\
\cline { 2 - 3 } $\mathbf{5 0}$ to $\mathbf{7 5 \% )}$ & $\boldsymbol{n}$ & $\mathbf{\%}$ \\
\hline Caesarean section & 42 & 73.7 \\
Close reduction of fractures & 42 & 71.2 \\
Circumcision & 41 & 70.7 \\
Gastric washout & 41 & 69.5 \\
\hline Application of traction & 38 & 65.5 \\
Cauterisation of warts & 36 & 64.3 \\
Obstetric ultrasound & 37 & 63.8 \\
Skin biopsy & 36 & 63.2 \\
Umbilical vein catheterisation & 36 & 63.2 \\
Assisted breech delivery & 36 & 62.1 \\
Excision and incision biopsy & 36 & 62.1 \\
Laparotomy for ruptured ectopic & 36 & 62.1 \\
Repair of third degree tear & 36 & 62.1 \\
Spinal anaesthesia & 35 & 61.4 \\
Tubal ligation & 35 & 61.4 \\
Insertion of central venous line & 35 & 59.3 \\
Repair of lacerated eyelid & 34 & 59.0 \\
Paronychia drainage & 33 & 58.6 \\
Amputation of digits & 33 & 58.6 \\
Intrabursal/articular injections & 32 & 56.1 \\
Hydrocoele drainage & 31 & 54.4 \\
Aspiration of breast cyst & 31 & 52.5 \\
Excision of in growing toenail & 30 & 51.0 \\
Drainage of perianal haematoma & 29 & 50.9 \\
\hline & & \\
\hline
\end{tabular}

procedures independently (Tables 3-5). The participants reported being highly competent in doing procedures such as lumbar punctures (94.9\%), inter-costal drains (93.2\%) and endotracheal intubations $(86.2 \%)$, but not competent in procedures such as the intrauterine contraceptive device $(40.7 \%)$, appendicectomy $(37.3 \%)$ and cricothyroidotomy $(11.0 \%)$. Most of these participants (Table 2) reported experience of doing procedures more than 10 times with highly competent procedures compared to not competent procedures such as cricothyroidotomy where the doctors reported unfamiliarity with the procedure $(32.0 \%)$.

The participants reported being competent in performing procedures such as caesarean sections (C/S) (73.7\%) and spinal anaesthesia (61.4\%) (Table 3$)$. The participants 
reported not being competent in procedures such as venous cutdown (30.5\%), vasectomy $(13.8 \%)$ and pleural biopsy (Table 5).

Comparisons were performed using Chi-square and Fisher's exact tests between total scores of overall competence of a doctor in each set of procedures in one discipline and the main variables such as age, gender, years of experience, place of undergraduate study, discipline where they spent most of the time, family medicine training and the current hospital of employment (Table 6). Significant associations were found between age and overall anaesthetic competence $(p=0.03)$, as well as male gender and greater overall competence in general surgical skills $(p=0.03)$, orthopaedic skills $(p=0.02)$ and urology skills $(p=0.005)$, and years of experience and overall competence in dermatology skills. There were also significant associations between the current hospital and overall competence in anaesthesia $(p=0.01)$, O\&G skills $(p=0.015)$ and dermatology skills $(p=0.01)$. No significant associations were found between overall competence and place of undergraduate training and postgraduate family medicine training.

TABLE 5: Procedural skills in which doctors rated themselves as not competent.

\begin{tabular}{|c|c|c|}
\hline \multirow{2}{*}{$\begin{array}{l}\text { List of procedural skills in which } \\
\text { doctors rated themselves as not } \\
\text { competent (less than } 50 \% \text { ) }\end{array}$} & \multicolumn{2}{|c|}{$\begin{array}{l}\text { No. of doctors who could perform the } \\
\text { procedure independently }(n=59)\end{array}$} \\
\hline & $n$ & $\%$ \\
\hline General anaesthesia & 26 & 48.1 \\
\hline Intraosseous infusion & 26 & 46.4 \\
\hline Injection of keloids & 26 & 44.8 \\
\hline Posterior colpopuncture & 24 & 42.1 \\
\hline Insertion of IUCD & 24 & 40.7 \\
\hline Endometrial biopsy & 22 & 39.3 \\
\hline Appendicectomy & 22 & 37.3 \\
\hline Skin graft & 19 & 32.8 \\
\hline Venous cutdown & 18 & 30.5 \\
\hline Indirect laryngoscopy & 15 & 25.9 \\
\hline Proctoscopy & 14 & 24.6 \\
\hline I and D Meibomian cyst & 14 & 24.6 \\
\hline Pleural biopsy & 14 & 24.0 \\
\hline Bier's block & 8 & 16.7 \\
\hline Epidural anaesthesia & 8 & 14.0 \\
\hline Vasectomy & 8 & 13.8 \\
\hline Tracheostomy & 8 & 13.6 \\
\hline Cricothyroidotomy & 6 & 11.0 \\
\hline Tonometry & 4 & 6.9 \\
\hline
\end{tabular}

IUCD, Intrauterine contraceptive device.

\section{Discussion}

When assessing the 72 clinical procedures commonly done in peri-urban district hospitals, the doctors reported varying levels of competence and experience in the different groups of skills. The reported competence levels of doctors also varied according to different disciplines. They considered themselves to be less competent in anaesthesia; ear, nose and throat (ENT) and ophthalmology procedures than general surgery, medicine, orthopaedics, O\&G, urology and paediatric procedures. These findings were similar to other studies which identified skill gaps in emergency and anaesthetic procedures in district hospitals. ${ }^{9,11}$ The study findings were different to the other studies done in South Africa where GPs reported higher competence in doing surgical and O\&G procedures in urban settings. ${ }^{14,15}$ The competence of doctors in doing procedures varied depending on the type of procedures done and on the context of the hospital as seen in previous studies..$^{9,10,11,14}$

Among the emergency procedures such as cricothyroidotomy and intraosseous infusion, doctors reported less competence in doing these independently; this is reiterated in other studies done in South Africa. ${ }^{11,27}$ Being rare events, ${ }^{28}$ doctors seldom need to perform these procedures in rural or urban settings. However, as these are emergency procedures, ideally all doctors should be able to perform them independently. This emphasises the importance of ongoing doctor training in emergency courses such as Basic Emergency Skills Training or Advanced Trauma Life Support. ${ }^{27}$

Among the anaesthetic procedures, most doctors were competent in performing spinal anaesthesia, while fewer than half of the doctors reported being able to do general anaesthesia independently. The latter finding was not reiterated compared to other studies done in rural settings; this could have been because of the differences in study designs. ${ }^{9,10,11}$ Ability to perform spinal and general anaesthesia is important because, firstly, spinal anaesthesia is a requirement for common procedures such as caesarean sections done at district hospitals. Secondly, it is a clinical imperative that doctors are able to convert a failed spinal anaesthesia to general anaesthesia and take control of the airway and ventilation, preferably by intubation. Thirdly, the Saving Motherhood Initiative identifies inadequate

TABLE 6: Association of overall competence in procedural skills and demographic variables.

\begin{tabular}{|c|c|c|c|c|c|c|c|c|c|c|}
\hline \multirow[t]{2}{*}{ Demographic variables } & \multicolumn{10}{|c|}{ Overall competence in procedural skills* } \\
\hline & Anaesthesia & ENT & Surgery & O\&G & Orthopaedics & Medicine & Paediatrics & Ophthalmology & Dermatology & Urology \\
\hline Age & 0.03 & 0.57 & 0.86 & 0.65 & 0.72 & 0.96 & 0.52 & 0.39 & 0.53 & 0.87 \\
\hline Gender & 0.66 & 0.5 & 0.03 & 0.41 & 0.02 & 0.13 & 1 & 0.88 & 0.18 & 0.005 \\
\hline Years of experience & 0.41 & 0.97 & 0.67 & 0.09 & 0.84 & 0.86 & 0.2 & 0.78 & 0.02 & 0.12 \\
\hline $\begin{array}{l}\text { Discipline (where spent most } \\
\text { of the time) }\end{array}$ & 0.05 & 0.85 & 0.62 & 0.39 & 0.24 & 0.07 & 0.44 & 0.54 & 0.18 & 0.89 \\
\hline $\begin{array}{l}\text { Undergraduate study (in SA } \\
\text { or outside SA) }\end{array}$ & 0.77 & 0.31 & 0.23 & 0.34 & 0.52 & 0.14 & 0.35 & 0.47 & 0.75 & 0.44 \\
\hline Family medicine training & 0.6 & 0.3 & 0.69 & 0.26 & 0.59 & 0.87 & 0.91 & 0.6 & 0.74 & 0.28 \\
\hline Current hospital & 0.01 & 0.19 & 0.15 & 0.015 & 0.16 & 0.94 & 0.78 & 0.05 & 0.01 & 0.26 \\
\hline
\end{tabular}

ENT, ear, nose and throat; O\&G, obstetrics and gynaecology; SA, South Africa.

$*, p$ values. 
competence in $\mathrm{C} / \mathrm{S}$ as a major factor contributing to maternal mortality in mothers in district hospitals. ${ }^{29} \mathrm{All}$ doctors should be trained to have adequate experience in doing $\mathrm{C} / \mathrm{S}$ and general anaesthesia independently which are core competencies for doctors required at district hospital level.

It is an interesting finding in this study that doctors assessed themselves as not competent in doing simple procedures like IUCD insertion, whereas they are competent in more complicated procedures such as tubal ligation and laparotomy for a ruptured ectopic. This may be because of not practising some of these skills. ${ }^{15,16,30}$ These procedures were not routinely done at district hospital level at the time but mostly done in primary health care (PHC) clinics. Currently, nurse practitioners perform simple procedures such as IUCD insertion in clinics, but if there are complications, generalist doctors in district health services manage them. This suggests that there is a need for rotation of generalist doctors within all levels of the district health system, to ensure appropriate exposure to skills performed at that level.

The data show that the doctors self-reported as being incompetent in procedures such as epidural anaesthesia, appendicectomy, proctoscopy and pleural biopsies, not routinely performed in urban settings. These specialised skills are easily accessible at regional hospitals. These procedures were not done in adequate numbers in rural hospitals of Western Cape either, ${ }_{1}^{14}$ and this reiterates the need for context-specific skill sets in urban and rural district hospital settings.

The NHI white paper towards UHC specifies family medicine, $O \& G$, paediatrics and general surgery as the four main domains for district hospitals in South Africa. ${ }^{3}$ This study shows reduced competency in surgical procedures and highlights the need to bridge these gaps in a peri-urban district hospital setting. This will reduce the current overreliance on higher levels of care, leading to long waiting times and surgical backlogs. ${ }^{31}$

The overall reported competence in the different disciplines did not show any association with the different age groups in this study except for anaesthesia. The overall competence in anaesthetic skills was perceived as higher in the younger age group (25-34 years) than older doctors. The study by De Villiers showed greater self-reported competence in older doctors. ${ }^{11}$ This difference could be because of more clinical exposure of younger doctors to anaesthetic training during the mandatory 2-year internship and community service rotations, introduced in 2005 and 1999, respectively. Alternatively, more senior doctors who did not have mandatory exposure to anaesthetics during internship could be practising in disciplines that do not require anaesthetic skills, especially considering that more than half $(57.6 \%)$ worked in casualty and OPD at the time of the study.

The gender variations in the overall competency in surgical, orthopaedic and urology skills are significant, with male doctors reported as being more competent in the procedural skills in these disciplines than their female counterparts. ${ }^{32,33}$ This could, in part, be because of the self-reporting nature of the study, where female doctors tend to underestimate confidence in their abilities, especially in terms of competence, ${ }^{34,35}$ and therefore this finding may not be a true reflection of actual competence; if it was, lower workload, lifestyle and income are some of the other contributable factors for these female preferences as described in the literature. $^{36}$ This has implications for current and future human resource for health planning, where women are becoming a significant proportion of the medical workforce. ${ }^{37}$

The self-perceived overall competence in dermatological skills had a significant association with years of experience and this may be because doctors were routinely performing common procedures such as cauterisation, skin biopsies and excision of bumps and lumps. ${ }^{38}$

The overall competence reported on various skill sets did not demonstrate any differences based on undergraduate training, within or outside of South Africa. Given that approximately half of the medical doctors in the study were foreign qualified, ${ }^{39}$ assessing their procedural competencies had to be a consideration for service delivery. It is beyond the scope of this study to determine if the foreign qualified doctors in this study were competent in these procedures prior to or after coming to South Africa, as the majority of these doctors had more than 10 years of working experience in South Africa.

Family medicine training has evolved in South Africa, from the initial part-time Masters in Family Medicine (M Fam Med) programme to the current full-time Masters in Medicine in the branch of Family Medicine (M Med Family Medicine) programme started in 2008. One of the main refinements to the new MMed programme was the subsequent development of a standardised clinical skill set for family medicine registrars. ${ }^{19}$ The doctors in this study exposed to family medicine training were doing the M Fam Med, and there was no difference between their procedural skills and others. The current full-time M Med registrar programme has been running for 10 years now; it is an opportune period to explore and study the procedural skills competencies of these graduates, to determine if, indeed, there is improvement compared to the current revised skills list. ${ }^{40}$ Family physicians have a big role to play in PHC and the long-term goal should be to develop a critical mass of skilled family physicians who can fulfil the key roles of a care provider, supervisor and capacity builder to other cadres of health workers in the district health services. ${ }^{8}$

The study also found that the doctors working in one district hospital showed an overall higher reported competence in doing anaesthesia and O\&G procedures than doctors working in the other two hospitals. The central question was 'What was different in this one hospital?' This difference may have been because of doctors regularly rotating among the different domains in the one hospital compared to the others, 
where doctors had worked in the same domains for years. In theopinion of theauthors, thiselementof 'departmentalisation' within a district hospital is not ideal in developing generic and cross-cutting procedural skills competencies. Emphasis should be on developing competencies in all the required skills needed for a district hospital level such as in the current family medicine registrar programme.

As this was a self-assessment study, there was potential for information bias, so competencies reported may not have been the actual competence of the participant. Both competence and experience were self-reported and may have been under- or overestimated. The smaller sample size in some of the groups could have affected the power of the study and results. Lastly, this was a cross-sectional study and cannot infer a causal relationship in the associations determined. This design is also a snap shot in time and precludes any inferences regarding longitudinal relationships.

\section{Conclusion}

The self-assessment tool used in this study offered a valuable way of measuring the study objectives and could be used to evaluate the skills of doctors working in district hospitals in other areas or districts in similar settings. This study found variable reported procedural skills competencies among doctors in district hospitals in the southern Gauteng Province, especially in medicine, paediatric, $O \& G$, orthopaedic, surgical and anaesthetic procedures. To the extent that these findings have implications for service delivery and training in the district; interventions aimed at bridging these skill gaps need to take cognisance of variations in sociodemographic and workplace characteristics. There should be provision for generalist doctors and specialists, such as family physicians, to practise a wide range of procedural skills dependent on their experience and competence in a district hospital setting, based on ruralurban contexts and district service delivery packages.

\section{Acknowledgements}

The authors acknowledge Tonderai and Tabitha for their additional statistical analysis support and O.B.O. and C.D. for additional corrections to the manuscript. At the time of the study, N.J.E. was a postgraduate student at the Department of Family Medicine, University of the Witwatersrand, Johannesburg, South Africa.

\section{Competing interests}

The authors did not receive any funding or grant from any entity and declare that they have no conflicts of interest.

\section{Authors' contributions}

N.J.E. was the principal investigator. N.J.E., I.D.C and L.S.T. were involved in the study conceptualisation and manuscript development. N.J.E. was responsible for the data collection and I.D.C. supervised the study.

\section{Data availability statement}

Data sharing is not applicable to this article as no new data were created or analysed in this study.

\section{Disclaimer}

The views and opinions expressed in this article are those of the authors and do not necessarily reflect the official policy or position of any affiliated agency of the authors.

\section{References}

1. Health Systems in Action an eHandbook for Leaders.pdf [home page on the Internet]. [cited 2017 Jul 21]. Available from: http://www.msh.org/sites/msh.org/ files/msh_ehandbook_complete.pdf

2. Universal Health Coverage I - The World Health Organization on UHC and South Africa [home page on the Internet]. Helen Suzman Foundation. [cited 2018 Aug 01]. Available from: https://hsf.org.za/publications/hsf-briefs/universalhealth-coverage-i-the-world-health-organization-on-uhc-and-south-africa.

3. National-Health-Insurance-for-South-Africa-White-Paper.pdf [home page on the Internet]. [cited 2017 Apr 20]. Available from: https://www.health-e.org.za/wpcontent/uploads/2015/12/National-Health-Insurance-for-South-Africa-WhitePaper.pdf.

4. WHO | Health Systems Strengthening Glossary [homepage on the Internet]. WHO [cited 2019 Jan 31]. Available from: https://www.who.int/healthsystems/hss_ glossary/en/index3.html.

5. Department of Health. A district hospital service package for South Africa: A set of norms and standards homepage on the Internet]. Pretoria: Department of Health 2002 [cited 2011 Feb 20] Available from: http://www.kznhealth.gov.za/norms.pdf.

6. Howe AC, Mash RJ, Hugo JFM. Developing generalism in the South African context. S Afr Med J [serial online]. 2013 Oct 11 [cited 2019 Feb 02];103(12):899-900 Available from: http://www.samj.org.za/index.php/samj/article/view/7509.

7. Reid SJ, Mash R, Downing RV, Moosa S. Perspectives on key principles of generalist medical practice in public service in sub-Saharan Africa: A qualitative study. BMC Fam Pract [serial online]. 2011 Dec [cited 2016 Jun 20];12(1). Available from: http://bmcfampract.biomedcentral.com/articles/10.1186/1471-2296-12-67.

8. Mash R, Ogunbanjo G, Naidoo SS, Hellenberg D. The contribution of family physicians to district health services: A national position paper for South Africa. S Afr Fam Pract. 2015;57(3):54-61.

9. Reid SJ, Chabikuli N, Jaques PH, Fehrsen GS. The procedural skills of rural hospital doctors. S Afr Med J. 1999 Jul;89(7):769-774.

10. De Villiers MR, De Villiers PJT. Theatre and emergency medical services rendered by general medical practitioners in District hospitals in Western Cape. S Afr Fam Pract. 2003;45(47):15-19.

11. De Villiers MR, De Villiers PJT. The knowledge and skills gap of medical practitioners delivering district hospital services in the Western Cape, South Africa. S Afr Fam Pract. 2006;48(2):16. https://doi.org/10.1080/20786204.2006.10873333

12. Solanke TP. Training of medical practitioners in Nigeria for surgery in the rura areas. S Afr J Surg. 1997;35(3):139-141.

13. Chiasson PM, Roy PD. Role of the general practitioner in the delivery of surgical and anaesthesia services in rural western Canada. CMAJ Can Med Assoc J [serial online]. 1995 Nov 15 [cited 2018 Jul 31];153(10):1447-1452. Available from https://www.ncbi.nlm.nih.gov/pmc/articles/PMC1487430/.

14. Du Plessis D, Kapp PA, Jenkins LS, Giddy L. Postgraduate training for family medicine in a rural district hospital in South Africa: Appropriateness and sufficiency of theatre procedures as a sentinel indicator. Afr J Prm Health Care Fam Med. 2016;8(1):a1106. https://doi.org/10.4102/phcfm.v8i1.1106

15. Malan Z, Cooke R, Mash R. The self-reported learning needs of primary care doctors in South Africa: A descriptive survey. S Afr Fam Pract. 2015:57(1):35-43. https://doi.org/10.1080/20786190.2014.1002677

16. Peters F, Van Wyk J, Van Rooyen M. Intern to independent doctor: basic surgical skills required for South African practice and interns' reports on their competence. S Afr Fam Pract [serial online]. 2015 Jul 4 [cited 2016 Jul 31];57(4):261-6. Available SAfr Fam Pract [serial online]. $2015 \mathrm{Jul} 4$ [ cited 2016 Jul 31];57(4):261-6. Availab
from: https://www.tandfonline.com/doi/full/10.1080/20786190.2014.976954.

17. Mash R, Reid S. Statement of consensus on Family Medicine in Africa. Afr J Prim Health Care Fam Med [serial online]. 2010 Mar 12 [cited 2016 Jan 20];2(1):4. Available from: https://phcfm.org/index.php/phcfm/article/view/151.

18. Moosa S, Peersman W, Derese A, et al. Emerging role of family medicine in South Africa. BMJ Glob Health [serial online]. 2018 Sep 06 [cited 2019 Jan 31] 3(Suppl 3). Available from: https://www.ncbi.nlm.nih.gov/pmc/articles/PMC6135463/.

19. Mash B, Couper I, Hugo J. Building consensus on clinical procedural skills for South African family medicine training using the Delphi technique. S Afr Fam Pract. 2006;48(10):14-14e. https://doi.org/10.1080/20786204.2006.10873475

20. Connick RM, Connick P, Klotsas AE, Tsagkaraki PA, Gkrania-Klotsas E. Procedural confidence in hospital based practitioners: Implications for the training and practice of doctors at all grades. BMC Med Educ. 2009 Jan 12;9(1):2. https://doi. org/10.1186/1472-6920-9-2

21. Nothnagle M, Sicilia JM, Forman S, et al. Required procedural training in family medicine residency: A consensus statement. Fam Med. 2008 Apr;40(4):248-252. 
22. Wetmore SJ, Rivet C, Tepper J, Tatemichi S, Donoff M, Rainsberry P. Defining core procedure skills for Canadian family medicine training. Can Fam Physician. 2005;51(10):1364-1365.

23. Goertzen J. Learning procedural skills in family medicine residency: Comparison of rural and urban programs. Can Fam Physician. 2006;52(5):622-623.

24. Kelly M, Everard KM, Nixon L, Chessman A. Untapped potential: Performance of procedural skills in the Family Medicine clerkship. Fam Med. 2017 Jun;49(6): 437-442.

25. Kalu QN, Eshiet Al, Ukpabio El, Etiuma AU, Monjok E. A rapid need assessment survey of anaesthesia and surgical services in district public hospitals in Cross River State, Nigeria. 2014;7(4):9.

26. Dean AG, Arner TG, Sunki GG, et al. Epi Info ${ }^{T M}$, a database and statistics program for public health professionals. Atlanta, GA: Centers for Disease Control and Prevention; 2007

27. Dufourq N, Nicole Goldstein L, Botha M. Competence in performing emergency skills: How good do doctors really think they are? Afr J Emerg Med [serial online] 2017 Dec [cited 2018 Jun 20];7(4):151-156. Available from: http://linkinghub. elsevier.com/retrieve/pii/S2211419X16301768.

28. Schauer SG, Bellamy MA, Mabry RL, Bebarta VS. A comparison of the incidence of cricothyrotomy in the deployed setting to the emergency department at a level 1 Military Trauma Center: A descriptive analysis. Mil Med. 2015 Mar 01 180(Suppl_3):60-63. http://doi.org/10.7205/MILMED-D-14-00384

29. National Committee on Confidential Enquiries into Maternal Deaths. Saving mothers 2005-2007: Fourth report on confidential enquiries into maternal deaths in South Africa. Expanded Executive Summary. Pretoria, South Africa: NCCEMD; 2007.

30. Patel M, Oosthuizen G, Child S, Windsor JA. Training effect of skills courses on confidence of junior doctors performing clinical procedures. N Z Med J. 2008 Jun 6;121(1275):37-45.

31. Annual report 2013/2014 [home page on the Internet]. Johannesburg, South Africa: Gauteng Department of health; [cited 2018 Dec 04]. pp. 67-71. Available from: https://provincialgovernment.co.za/department annual/162/ 2014-gauteng-health-annual-report.pdf.
32. Fukuda $Y$, Harada T. Gender differences in specialty preference and mismatch with real needs in Japanese medical students. BMC Med Educ. 2010 Feb 11:10(1):15. https://doi.org/10.1186/1472-6920-10-15

33. Mwachaka PM, Mbugua ET. Specialty preferences among medical students in a Kenyan university. Pan Afr Med J [serial online]. 2010 Aug [cited 2011 Aug 31];5. Available from: http://www.panafrican-med-journal.com/content/article/5/18/ full/.

34. Gordon MJ. A review of the validity and accuracy of self-assessments in health professions training. Acad Med. 1991;66:762-769. https://doi.org/10.1097/ 00001888-199112000-00012

35. Ehrlinger J, Dunning D. How chronic self-views influence (and potentially mislead) estimates of performance. J Pers Soc Psychol. 2003;84:5-17. https://doi.org/ 10.1037/0022-3514.84.1.5

36. Lee CW. Gender difference and specialty preference in medical career choice, gender difference and specialty preference in medical career choice. Korean Med Educ Korean J Med Educ [serial online]. 2013 Mar 31 [cited 2017 Aug 20];25(1):15-21. Available from: http://kjme.kr/journal/view. php?number=340.

37. Khan T, Thomas LS, Naidoo S. Analysing post-apartheid gender and racial transformation in medical education in a South African province. Glob Health Action [serial online]. 2013 Jan 24. [cited 2016 Jun21];6. Available from: https:// www.ncbi.nlm.nih.gov/pmc/articles/PMC3556715/.

38. Hugo JFM, Hugo DM, Mawela L. Common conditions and task gap for midlevel medical workers in district hospitals in South Africa: Information to inform curriculum development. (Report to Human Resource Planning Directorate, National Department of Health, Pretoria) Brits: Madibeng Centre for Research 2005 (Unpublished).

39. Segatti A. A disposable workforce: Foreign health professionals in the South African public service. Migrating for Work Research Consortium (MiWORC) Report No7. Johannesburg: African Centre for Migration and Society, University of Witwatersrand; 2014.

40. Akoojee Y, Mash R. Reaching national consensus on the core clinical skill outcomes for family medicine postgraduate training programmes in South Africa. Afr $J$ Prim Health Care Fam Med. 2017;9(1):a1353. https://doi.org/10.4102/phcfm. v9i1.1353. 